\title{
Ailevi Akdeniz Ateşi Olan Çocuklarda Ortalama Trombosit Hacminin Klinik Önemi
}

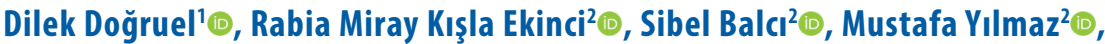 \\ Derya Ufuk Altıntaş'®i]
}

${ }^{1} C ̧ u k u r o v a$ Üniversitesi, Çocuk Alerji ve İmmünoloji, Adana, Türkiye ${ }^{2}$ Çukurova Üniversitesi, Çocuk Romatoloji, Adana, Türkiye

Dilek Doğruel, Doç. Dr. Rabia Miray Kışla Ekinci, Uzm. Dr. Sibel Balcı, Uzm. Dr. Mustafa Yılmaz, Prof. Dr. Derya Ufuk Altıntaş, Prof. Dr.

İletişim:

Doç. Dr. Dilek Doğruel Çukurova Üniversitesi, Çocuk Alerij ve İmmünoloji, Adana, Türkiye Tel: +90 5071632682

E-Posta: dilekkaragoz1977@hotmail.com
ÖZET

Amaç: Ailevi Akdeniz Ateşi (AAA), otozomal resesif geçiş gösteren inflamatuar bir hastalık olup seröz membranların tekrarlayan tutulumu ile karakterizedir. İnflamatuvar hastalıkların pek çoğunda ortalama trombosit hacminin (OTH) belirteç olarak kullanılabileceği gösterilmiştir. Bu çalışmada AAA'lı çocuklarda genetik mutasyon ile hastalığın ataklı ve ataksız dönemlerinde ortalama trombosit hacmindeki değişiklikleri inceledik.

Hastalar ve Yöntemler: Çalışmaya Tel-Hashomer kriterlerine göre AAA tanısı almış 110 çocuk dahil edildi. Hastaların demografik özellikleri, genetik tarama sonuçları, tam kan sayımı parametreleri, OTH düzeyleri, eritrosit sedimantasyon hızı (ESH), C-Reaktif protein (CRP) değerleri retrospektif olarak değerlendirildi. Hastaların verileri tedavi altında ataklı ve ataksız dönemlerine göre ayrı ayrı kaydedildi.

Bulgular: Ortalama trombosit hacmi ataklı dönemde 8,55 $\pm 1,51 \mathrm{fL}$ iken ataksız dönemde 9,61 $\pm 1,18 \mathrm{fL}$ saptandı. Hastaların ataklı dönem 0 TH düzeylerinde, ataksız döneme göre istatistiksel olarak anlamlı düşüktü $(p=0.000)$. Trombosit ve beyazküre sayıları, ESH ve CRP seviyeleri atak döneminde ataksız döneme göre istatistiksel olarak anlamlı yüksekti $(\mathrm{p}=0.000)$.

Sonuç: Ortalama trombosit hacmi hastaların atak döneminde düşmektedir ve bu atakları saptamada faydalı olabilir. Klinisyenin hemogram sonucunu değerlendirirken bu parametreyi kullanması önemlidir.

Anahtar sözcükler: Ailevi Akdeniz Ateşi, inflamasyon, ortalama trombosit hacmi

\section{CLINICAL IMPORTANCE OF MEAN PLATELET VOLUME IN CHILDREN WITH FAMILY MEDITERRANEAN FEVER}

\section{ABSTRACT}

Objectives: Familial Mediterranean Fever (FMF) is an autosomal recessive inflammatory disease characterised by recurrent involvement of serous membranes. It has been shown that the mean platelet volume (MPV) could be used as a marker in many inflammatory diseases. In this study, we investigated the genetic mutation in children with FMF and changes in MPV in attack and attack-free periods.

Patients and Methods: The study included 110 children diagnosed with FMF based on the Tel-Hashomer Criteria Demographic features, results of genetic analyses, complete blood count parameters, MPV levels, erythrocyte sedimentation rate (ESR), C-reactive protein (CRP) results were evaluated retrospectively. Data of the patients were recorded separately based on the acute attack and attack-free periods under treatment.

Results: The mean platelet volume was found to be $8,55 \pm 1,51 \mathrm{fL}$ in the attack period and $9,61 \pm 1,18 \mathrm{fL}$ in the attack-free period. The mean platelet volume was significantly lower in patients with an attack period compared to the patients at an attack-free period $(p=0.000$ ). The platelet and leukocyte count, $E S R, C R P$ were statistically significantly higher in the attack period compared to the attack-free period $(\mathrm{p}=0.000)$.

Conclusion: The mean platelet volume is decreased in patients with attack period and it may be a useful parameter in determining(timing) the attack. It is important that clinicians use this parameter when evaluating the hemogram result.

Keywords: Familial Mediterranean Fever, Inflammation, Mean Platelet Volume
Gönderilme Tarihi : 30 Mart 2018

Revizyon Tarihi : : 07 Mayıs 2018

Kabul Tarihi : : 13 Mayıs 2018 
A ilevi Akdeniz Ateşi (AAA), tekrarlayıcı ve kendini sınırlayıcı ateş ile birlikte poliserozit atakları ile karakterize kalıtsal bir hastalıktır. Klinik bulgulara, MEFV genindeki mutasyon sonucunda anormal pyrin proteininin sentezine bağlı olarak, enflamasyonun etkin olarak baskılanamaması neden olmaktadır (1). Atak döneminde akut faz proteinlerinde (eritrosit sedimentasyon hızı, C reaktif protein, fibrinojen) artış hastalığın karakteristik özelliklerindendir (2). Ailevi Akdeniz ateşi, alevlenmeler ile seyreden bir hastalık olarak bilinmesine rağmen hastalarda ataksız dönemde bile inflamasyonun devam ettiği gösterilmiştir (3). Ayrıca MEFV geninde M694V homozigot mutasyonun daha yüksek hastalık şiddeti skoru ve amiloidoz insidansı ile ilişkisi bildirilmiştir (4).

Trombosit hacmi, trombosit aktivasyonunu belirlemek için kullanılan bir parametredir ve ortalama trombosit hacmi (OTH) olarak gösterilmektedir (5). Yüksek MPV, hem metabolik hem de enzimatik açıdan aktif trombositleri ve artmış trombosit boyutunu gösterir (6). Trombosit hacmi kemik iliğinde megakaryositlerden trombosit gelişimi sırasında belirlenir, dolaşımdaki trombositlerde olgunlaşma olmaz. Bu nedenle kemik iliğinin uyarıldığı inflamasyon durumu, trombosit hacminde ve sayısında değişikliğe neden olabilmektedir. Ortalama trombosit hacminde görülen bu değişiklikler sayıca olan değişimden daha önce görülmektedir (7). Literatürde OTH'de görülen değişimin inflamasyonun erken döneminin belirlenmesinde yararlı olabileceği gösterilmiştir (8).

Bu çalışmada $A A A^{\prime} l ı$ çocuklarda hastalığın ataklı ve atakSIz dönemlerinde akut faz reaktanları ile birlikte ortalama trombosit hacmindeki değişikliklerin incelenmesi planlanmıştır.

\section{Hastalar ve yöntemler}

Çukurova Üniversitesi Tıp Fakültesi Çocuk İmmünoloji ve Alerji ile Romatoloji Polikliniğinde 2008-2017 yılları arasında Tel-Hashomer Kriterlerine göre AAA tanısı almış olup düzenli aralıklarla izlenen 110 hasta retrospektif olarak incelendi. Çalışmaya alınan hastalar; cinsiyet, başvuru anındaki yaşı, tanı yaşı, ateş, karın ağrısı, göğüs ağrısı, artralji, erizipel benzeri eritem ve genetik analiz sonuçları açısından incelendi. Laboratuvar parametreleri olarak; hemoglobin, beyaz küre, trombosit sayıları, OTH, eritrosit sedimentasyon hızı (ESH), C reaktif protein (CRP) düzeyleri kaydedildi. Tedavi esnasındaki ataklı ve ataksız dönemlerde yapılmış olan tetkikleri ayrı ayrı kaydedildi. Çalışma için Çukurova Üniversitesi etik kurulundan etik kurul onayı alındı (2017/60/58).

İstatistiksel analiz İstatistiksel degerlendirmede IBM SPSS Statistics 21,0 (SPSS Inc., Chicago, IL, ABD) programı kullanıldı. Tanımlayıcı veriler ortalama \pm standart sapma, sayılar ve yüzdelerle ifade edildi. Sürekli verilerin karşılaştırılmasında Student's t-test kulanıldı. $\mathrm{P}<0.05$ değeri istatistiksel olarak anlamlı kabul edildi.

\section{Bulgular}

Çalışmaya alınan tüm çocukların, 58'i $(\% 52,7)$ kız, 52'si $(\% 47,3)$ erkek ve ortalama yaş $11,44 \pm 4,29$ (ortanca: 11,81 ) yaşdı. Hastalığın klinik bulgularının başladığı ortalama yaş $54,58 \pm 39,06$ ay ( 6 ay- 15 yaş), ortalama tanı alma yaşı ise $7,08 \pm 4,14$ yıl ( 1 yaş-16 yaş) idi. Ortalama takip süresi $69,80 \pm 33,35$ aydı. Çalışmaya dahil edilen tüm hastalar kolşisin tedavisi almaktaydı.

Hastaların \%92,7'sinde $(n=102)$ ateş, \%90'da karın ağrısı $(n=99), \% 76,4$ 'de $(n=84)$ eklem ağrısı, \%10,9'da $(n=12)$ erizipel, \%9,1'de ( $n=10)$ apendektomi öyküsü mevcuttu. Çalışmaya alınan hastaların \%41,8'inde ( $n=46)$ MEFV geninde homozigot, \%25,4'ünde ( $\mathrm{n}=28)$ kompound heterozigot, \%32,8'inde $(n=36)$ heterozigot mutasyon mevcuttu (Tablo 1). En sık saptanan genotip ise MEFV geninde M694V homozigot $(\% 31,8, \mathrm{n}=35)$ mutasyondu.

Hastaların atakta ve atak dışı periodda ölçülen ortalama hemoglobin, lökosit, trombosit sayısı, OTH, ESH ve CRP düzeyleri arasında istatistiksel olarak anlamlı farklılık saptandı $(p<0.05)$ (Tablo 2). Hastalar M694V homozigot genotip varlığına göre sınıflandırıldığında ise; atak dışı dönemde ölçülen ortalama hemoglobin, beyaz küre, trombosit ve OTH düzeyleri arasında iki grup arasında istatistiksel olarak anlamlı farklılık yok iken, ESH ve CRP düzeyleri M694V homozigot genotipe sahip grupta diğer gruba kıyasla istatistiksel olarak anlamlı derecede yüksekti (Tablo 3).

\begin{tabular}{lcccc} 
Tablo 1. MEFV gen analiz sonuçları & \multicolumn{1}{c}{ Mutasyon tipi } & $n$ & $\%$ \\
\hline Homozigot & $\begin{array}{l}\text { M694V, M680I, R202Q, } \\
\text { V726A, E148Q }\end{array}$ & 46 & 41,8 \\
\hline Kompound heterozigot & $\begin{array}{l}\text { M694V/R202Q, M694V/E148Q, } \\
\text { M694I/E148Q, V726A/E148Q, } \\
\text { M694I/V726A, M680I/V726A, } \\
\text { E148Q/M680I, E148Q/R202Q }\end{array}$ & & \\
\hline Heterozigot & $\begin{array}{l}\text { E148Q, R202Q, M694V, } \\
\text { V726A, R761H, M680I, M694I, }\end{array}$ & 25,4 & 32,8 \\
\hline
\end{tabular}


Tablo 2. Hastaların atak ve atak dışı period laboratuar bulguları

\begin{tabular}{lccc} 
& Atak periodu & Atak dışı period & $p$ \\
\hline $\mathrm{Hb}(\mathrm{g} / \mathrm{dl})$ & $11,61 \pm 1,29$ & $12,43 \pm 1,15$ & $<0.001$ \\
Lökosit $\left(/ \mathrm{mm}^{3}\right)$ & $10633,54 \pm 4350,77$ & $7990,90 \pm 2042,99$ & $<0.001$ \\
Trombosit $\left(/ \mathrm{mm}^{3}\right)$ & $343192 \pm 111335$ & $319844 \pm 71710$ & 0.022 \\
OTH (fL) & $8,55 \pm 1,51$ & $9,61 \pm 1,18$ & $<0.001$ \\
ESH $(\mathrm{mm} / \mathrm{h})$ & $33,36 \pm 22,59$ & $7,90 \pm 7,85$ & $<0.001$ \\
CRP $(\mathrm{mg} / \mathrm{dl})$ & $7,28 \pm 5,53$ & $0,43 \pm 0.37$ & $<0.001$
\end{tabular}

Hb: Hemoglobin, OTH: Ortalama trombosit hacmi, ESH: Eritrosit sedimentasyon hızl, CRP: C-reaktif protein

Tablo 3. Atak dışı dönemde M694V Homozigot genotip durumuna göre laboratuar bulgularının karşılaştıııması

\begin{tabular}{lccc} 
& $\begin{array}{c}\text { M694V Homozigot } \\
\text { genotip grubu } \\
(\boldsymbol{n}=35)\end{array}$ & $\begin{array}{c}\text { M694V Homozigot } \\
\text { dişı genotip grubu } \\
(\boldsymbol{n}=75)\end{array}$ & $\boldsymbol{p}$ \\
\hline $\mathrm{Hb}(\mathrm{g} / \mathrm{dl})$ & $12,15 \pm 1,10$ & $12,55 \pm 1,16$ & 0.084 \\
Lökosit $\left(/ \mathrm{mm}^{3}\right)$ & $7788,57 \pm 2141,28$ & $8096,21 \pm 2014,65$ & 0.478 \\
Trombosit $\left(/ \mathrm{mm}^{3}\right)$ & $305571,43 \pm 72963,44$ & $327040,54 \pm 70638,46$ & 0.152 \\
OTH & $9,49 \pm 1,40$ & $9,65 \pm 1,06$ & 0.561 \\
ESH $(\mathrm{mm} / \mathrm{h})$ & $11,54 \pm 9,80$ & $5,96 \pm 5,91$ & 0.003 \\
CRP $(\mathrm{mg} / \mathrm{dl})$ & $0,60 \pm 0,45$ & $0,34 \pm 0,27$ & 0.003
\end{tabular}

Hb: Hemoglobin, OTH: Ortalama trombosit hacmi, ESH: Eritrosit sedimentasyon hIzl, CRP: C-reaktif protein

\section{Tartışma}

Çalışmamızda AAA'li hastalarımızın atak esnasında ölçülen beyazküre, trombosit sayıları ve akut faz reaktanları atak dışı dönemde ölçülen düzeylere göre istatistiksel anlamlı olarak daha yüksek saptandı. Bu sonuçların atak esnasındaki inflamasyona bağlı olduğunu düşündük. Bir başka bulgumuz ise atak esnasında ölçülen OTH düzeyinin daha düşük oluşu idi.

Literatürde AAA'li hastalarda OTH'nin değerlendirildiği çaIışmalar mevcuttur fakat birbiri ile çelişkili sonuçlar bildirilmiştir. Makay ve arkadaşları, OTH'nin atak dönemlerinde ataksız döneme göre daha düşük düzeyde iken, ataksız dönem ile kontrol grubu karşılaştıııldığında OTH açısından anlamlı bir fark bulunamadığını bildirmişlerdir (9). Çoban E ve arkadaşlarının yaptıkları çalışmada ise $A A A^{\prime} ı$ hastalar ile kontrol grubunun OTH düzeyleri karşılaştırıldığında $A A A^{\prime}$ Iı hastalarda OTH düzeyleri daha yüksek saptanmıştır (10). İnflamatuvar durumlar, kemik iliğinde trombosit üretiminin atmasına ve daha iri olan genç trombositlerin dolaşıma çıkmasına neden olur. Bu nedenle inflamasyonda OTH ve trombosit sayısında artış olması beklenir. Trombositlerin inflamasyonda etkin rol oynamaları nedeni ile inflamatuvar hastalıklarda trombosit sayısı artmaktadır. Fakat inflamasyonda OTH düzeylerinde düşmenin kesin nedeni tam olarak bilinmemektedir. Ailevi Akdeniz Ateşi inflamatuvar bir hastalık olup yapılan çalışmalarda akut faz reaktanlarının yanında IL-6 başta olmak üzere birçok sitokin düzeyinde yükselme görülmektedir (11). Bazı yazarlar enflamasyonda meydana gelen sitokin fırtınasının, özellikle IL-6 artışııı trombopoez uyarımına bağlı olarak OTH düzeylerinde azalmaya neden olabileceğini bildirmektedirler $(8,12)$. İnflamatuvar durumların trombosit membranı ve iç yapısında değişikliğe neden olduğu bildirilmektedir. İnflamasyon esnasında trombositlerin mikrotübüler yapısındaki depolimerizasyon ve aktin polimerizasyon yapısında meydana gelen değişikliklerin trombosit şeklini değiştirdiği ve bu değişikliğin OTH değerine yansıdığı düşünülmektedir. Bu konuyla ilgili diğer bir yaklaşım ise inflamasyon öncülü aracıların salınımında daha aktif olan büyük trombositlerin inflamasyon sahasına göçü ile dolaşımda göreceli olarak azalmasına bağlanabilir. Enflamasyon durumunda büyük trombositlerin fazla tüketilmesine bağlı olarak OTH'nın azaldığı düşünülmektedir (13). Bizim çalışmamızda, atakla beraber OTH düzeylerinde düşme görülürken, trombosit düzeylerinde anlamlı bir yükseklik saptanması trombopoezin rolü ile birlikte enflamasyonda büyük trombositlerin tüketimine ikincil OTH düşmesini akla getirmektedir.

Literatürde, M694V homozigot genotipine sahip hastalarda hastalığın daha ağır ve ciddi formunun görüldüğü, bu mutasyonun erken başlangıç yaşı, plörezi siklığı, artrit sıklığı ve artmış amiloidoz sıklığı ile ilişkili olduğunu göstermişlerdir $(14,15)$. Çalışmamızda M694V homozigot genotipe sahip olgularda atak dışı dönemde ESH ve CRP düzeylerini diğer genotipe sahip hastalara göre istatistiksel olarak anlamlı yüksek saptadık. Ortalama trombosit hacmi düzeyleri arasında ise anlamlı bir farklılık yoktu. Bu sonuç bize atak dışı dönemde de subklinik bir inflamasyonun varlığını göstermesi açısından önemli olsa da OTH'de herhangi bir değişikliğe sebep olmadığını düşündürmüştür.

Sonuç olarak çalışmamızda OTH'nın enflamasyonun daha belirgin olduğu atak dönemlerinde düşme eğiliminde olduğunu gösterdik. AAA'li hastalarda atak döneminde kan sayımı sonucu değerlendirilirken OTH değerinin de yorumlanmasının önemli olduğunu düşünmekteyiz. Bununla beraber daha geniş kapsamlı çalışmalarla sonuçlarımızın desteklenmesi OTH'nın klinik uygulamalarda daha güvenilir bir parametre olarak yer edinmesini sağlayacaktır 


\section{Kaynaklar}

1. Abuhandan M, Kaya C, Güzelçiçek A. Ailevi Akdeniz ateşi tanısı alan 186 olgunun klinik semptom ve MEFV geni mutasyonlarının incelenmesi. Dicle Tıp Derg 2015;42:61-5. [CrossRef]

2. Çobankara V, Balkarlı A. Ailesel Akdeniz Ateşi. Pamukkale Tıp Derg 2011;:86-98.

3. Ahsen A, Ulu MS, Yuksel S, Demir K, Uysal M, Erdogan M, Acarturk G. As a new inflammatory marker for familial Mediterranean fever: neutrophil-to-lymphocyte ratio. Inflammation 2013;36:1357-62. [CrossRef]

4. Padeh S, Shinar Y, Pras E, Zemer D, Langevitz P, Pras M, Livneh A. Clinical and diagnostic value of genetic testing in 216 Israeli children with familial Mediterranean fever. J Rheumatol 2003;30:185-90.

5. Morrell CN, Aggrey AA, Chapman LM, Modjeski KL. Emerging roles for platelets as immune and inflammatory cells. Blood 2014;123:275967. [CrossRef]

6. Martin JF, Shaw T, Heggie J, Penington DG. Measurement of the density of human platelets and its relationship to volume. $\mathrm{Br} J$ Haematol 1983;54:337-52. [CrossRef]

7. Bessman JD, Gilmer PR, Gardner FH. Use of mean platelet volume improves detection of platelet disorders. Blood Cells 1985;11:127-35.

8. Kisacik B, Tufan A, Kalyoncu U, Karadag O, Akdogan A, Ozturk MA, et al. Mean platelet volume (MPV) as an inflammatory marker in ankylosing spondylitis and rheumatoid arthritis. Joint Bone Spine 2008;75:291-4. [CrossRef]
9. Makay B, Türkyılmaz Z, Ünsal E. Mean Platelet Volume in children with familial mediterranean fever. Clin Rheumatol 2009;28:975-8. [CrossRef]

10. Çoban E, Adanır H. Platelet activation in patients with Familial Mediterranean Fever. Platelets 2008;19:405-8. [CrossRef]

11. Baykal Y, Saglam K, Yılmaz, Taşlıpınar A, Akıncı SB, İnal A. Serum IL-2, IL6, IL-10, TNFa level in familial mediterranean fever patients. Clin Rheumatol 2003;22:99-101. [CrossRef]

12. Yüksel O, Helvacı K, Başar Ö, Köklü S, Caner S, Helvacı N, et al. An overlooked indicator of disease activity in ulcerative colitis: Mean platelet volume. Platelets 2009;20:277-81. [CrossRef]

13. Gasparyan AY, Sandoo A, Stavropoulos-Kalinoglou A, Kitas GD. Mean platelet volume in patients with rheumatoid arthritis: the effect of anti-TNF-alpha therapy. Rheumatol Int 2010;30:1125-9. [CrossRef]

14. Cazeneuve C, Sarkisian T, Pecheux C, Dervichian M, Nédelec B, Reinert $P$, et al. MEFV gene analysis in Armanian patients with Familial Mediterranean fever: Diagnostic value and unfavorable renal prognosis of M694V homozygous genoytpe --genetic and therapeutic implications. Am J Hum Genet 1999;65:88-97. [CrossRef]

15. Gershoni-Baruch R, Brik R, Lidar M, Shinawi M, Livneh A. Male sex coupled with arthicular manifestations cause a 4-fold increase in susceptibility to amyloidosis in patients with Familial Mediterranean Fever homozygous for the M694V-MEFV mutation. J Rheumatol 2003;30:308-12. 